\title{
Evaluation of the potential improvements in freight rail transport: the case of a Swedish rail company
}

\author{
V. Roso ${ }^{1}$, S. Hagman ${ }^{1}$, M. de Nuria Calvo Mateo ${ }^{1} \&$ N. Brnjac ${ }^{2}$ \\ ${ }^{1}$ Chalmers University of Technology, \\ Logistics and Transportation, Sweden \\ ${ }^{2}$ University of Zagreb, Faculty of Transport and Traffic Science, Croatia
}

\begin{abstract}
Although rail transport is considered as energy efficient and environmental friendly mode of transport there are many hindrances towards increased use of rail for freight transport. The two main hindrances identified in Sweden are priority of passenger over freight rail transport and the fact that rail network has almost reached its capacity. Therefore the purpose of the paper is to evaluate potential improvements in the freight rail transport related to different areas of capacity utilization on a case of a rail company in Sweden. For this qualitative study the data is collected through interviews with the company's employees, both on operational and management level, as well as with Swedish Transport Authority. Analysed improvement areas with focus on capacity utilization include optimization of the maximum capacity of each train on a specific route and the formation of more even freight flow with limited variation both during a day as well as during a week. The findings show that operations could be significantly improved if the following suggestions are taken into consideration; focus on local planning, creation of anchor blocks, establishment of customers priority system and repositioning of the main shunting yard.

Keywords: rail freight transport, capacity utilization, anchor blocks, customer priority.
\end{abstract}

\section{Introduction}

Intermodal rail-road transport has long been promoted by the European Union (EU), and the EU has supported the development process of the rail-based intermodal transports [1]. However, despite the policies, the share of goods 
transported by rail in EU is only 10\% [2]. Last decade trend indicates that rail transport market share has continuously decreased compared to road which has experienced growth [2]. This is mainly due to flexibility offered by road, unreliability of intermodal transport due to complexity of the chain [3] as well as avoidance of extra transhipments. However, rail is considered to be much more environment friendly, in particular in Sweden where more than $90 \%$ of rail is electrified [4]. Furthermore one train can substitute approximately 35 lorries (in Europe) and consequently reduce external effects along the route not only due to lower emissions but also due to lower road congestion [4]. EU transport policies emphasize the need of optimizing current transport processes as well as turning transport into a more sustainable sector under economic, social and environmental points of view [5]. In order to achieve those objectives, an important approach would be revitalization and optimization of freight rail transport sector.

Rail transport in Sweden is very much in use, e.g. Port of Gothenburg, the biggest container port in Scandinavia, transports more than $40 \%$ of its 900,000 TEUs by rail to inland destinations, and there are 24 rail shuttles for different destinations that run daily services from/to the port [6]. The increase in rail transport in Sweden, especially for passenger transport, has resulted in high risk for traffic disruptions. On some routes, inadequate rail and road capacity is already a significant concern, with an increasing risk of traffic congestions, according to the Swedish Transport Administration's capacity investigation [7]. Other problem is in numerous rail companies interested in operating along these routes and therefore in urgent need for new slots. Only during 2010 a total of 47 Swedish rail companies, both in the passenger and freight transport sectors, applied to the Swedish Transport Administration for slot allocations [7]. One of the potential solutions to the existing rail network problem is to move goods from rail to short sea shipping, but it is on a longer time perspective and still in development [8]. Another long-time perspective solution according to [7] is enlargement of the rail network especially along high-utilized routes. Fast improvements are urgently needed and the rail company, in the studied case, identified 2 main areas for improvements: capacity optimization area and staff optimization area. In this paper only capacity optimization will be presented due to space limitations.

Therefore the purpose of the paper is to evaluate potential improvements in the freight rail transport related to different areas of capacity utilization. The idea is to analyse and evaluate the feasibility of identified improvements related to capacity utilization and to suggest implementation of those that have highest potential to increase efficiency of the services.

\section{Research approach}

A qualitative research strategy by use of case study based on interviews is applied in this study in order to increase understanding and provide in-depth analysis of the problem areas. One of the biggest Swedish rail freight company, owned by the Swedish government, has been used as a case since the 
company was eager to try to improve the present situation by increasing efficiency; to find solutions to their problems. According to [9], the main strength of the case research is that it can lead to creative insights and development of theory/models. The qualitative approach provides researchers with access to deeper levels of understanding of new phenomena, providing a high level of detail [10]. The main disadvantage of case study research method is that it is difficult to make a general conclusion based on the case results, as each study is unique [11]. In order to ensure validity, triangulation [9, 10] with multiple means of data collection has been done. Data was collected through face-to-face interviews during multiple site visits as well as trough videoconferences. Furthermore secondary data such as internal company reports, business oriented publications, web-based documents and archival records were used as well. Additionally some phone interviews as well as e-mail correspondence were done in order to fill the gaps.

To ensure reliability of the interviews, an interview protocol with open-ended questions has been developed [9] and the permission of interviewees to record the interview was obtained. A semi-structured interview was chosen as the appropriate method to explore the issues, as it allowed the interviewees to introduce new issues and the interviewer to follow up topics. Altogether 14 interviews have been conducted with people representing different levels of the company from operational level (shunters, drivers and planers) till management level (managers, analysts and strategic planers). Additionally an interview with capacity distributer from Swedish Transport Administration has been done as well.

\section{Frame of reference}

Passenger transport on rail has priority over freight on rail in Sweden. In the 1990s, the rail freight train traffic in Sweden was quite constant and without bigger plans for development [7]. During the same time period the road transports were increasing considerably as a result of the increased maximum weight for truckloads, increased maximum length for the trucks as well as the dropped additional taxes for kilometre driven; resulting in a major cost decrease for road transport [7]. Contrary to the forecast of the development of different freight transport modes between 1997 and 2010, containers on rail increased significantly [7], look at e.g. Port of Gothenburg containers on rail [8]. The forecast for different passenger traffic transportations was as wrong as well, and the major increase in the passenger rail traffic during the period was on the local train lines connecting the major cities of Stockholm, Gothenburg and Malmö [7]. That same bad forecast is one of the reasons of low investments in rail development.

\subsection{Allocation of capacity in the rail industry}

The allocation of the rail capacity among the train companies usually is done by specialized agencies dependant of the national governments, and three of the 
most important mechanisms used to determine the final allocation of the rail capacity are administered, cost based and market based mechanisms.

With administered mechanisms rail capacity is allocated according to different train priority levels established by the national agencies in charge of doing this task [12]. Cost based mechanism tries to achieve an efficient allocation of the railway capacity by setting different prices depending on which route and what time traffic band certain firms use. In addition, an extra fee is set for using those paths with high congestion levels [12]. Through market based mechanisms train companies apply for their desired time slots to their associated national allocation agency. Once all train companies have applied, the agency chooses that timetable which combines different firms providing the maximum profit [12].

The most critical routes in Sweden with biggest capacity and quality problems are those trafficked by both freight and passenger trains. At those routes there are lot of conflicts between the freight and the passenger trains, concerning the time slots given by Swedish Transport Administration who is in charge of it [13]. The most common reasons for a freight train to be delayed is to get into virtual nodes to let the passenger trains pass by and it increases costs for extra driver's hours as well as required engine hours [14].

\subsection{Rail freight companies management}

Rail operations are affected by the physical network constraints as well as by some policies such as train locomotive scheduling, empty wagons management, or wagon blocking. Problems linked to the interrelationship among those factors make the freight transport industry less efficient and may explain the continuous decreasing of freight transport market share [15]. Efficiency in freight rail transportation is closely linked to how well train operating and train scheduling policies are managed to get to a common direction [16]. While operating plans are related to train routing or the wagons blocking strategies; train scheduling policies are linked to the temporal dimension, considering the constraints linked to the need of synchronize working timetables with other rail companies: both in freight and passenger transport [16]. Operating policies comprise activities such as blocking, routing and makeup freight traffic, as well as manage the empty wagons flow. It is custom in the rail systems around the world to follow a type of "go when full" policy. Even when schedules were introduced they were mostly used as guidelines and trains were still sent off the schedule if they were fully loaded. But the very high volume of passenger trains in the system and the aspiration to decrease the total transport time of freight has forced the European rail companies to introduce more strict schedules for the freight transports. The Swedish railways have already worked in accordance to this for quite some time and used a similar booking system for the freight transports as for the passenger ones. 


\subsection{The three levels methodology for capacity planning}

Rail transportation capacity management and planning is done on three time horizon levels: strategic, tactical and operational, from a longer to a shorter time perspective respectively [15]. The strategic planning determines the preliminary solutions required to cover future demands, for example, setting the acquisition of long-lasting resources such as locomotives or the building of new infrastructures or stations. The tactical planning refers to medium and short-term aspects, for example the determination of the required rail slots to fulfil customer orders. Finally, the operational planning is linked to the daily control and management of freight rail firm's activities, facing and solving last minute problems such as accidents in the rail, or customer delays [15]. When analysing train capacity, it is necessary to distinguish between theoretical and practical capacity. Theoretical capacity refers to the maximum weight that certain train is able to transport, whereas practical capacity considers the feasible and real transport possibilities after including operational and reliability aspects. For that reason, practical capacity is that one used when planning transport activities [15].

\subsection{Different customers requirements}

There are several types of customer groups that can be identified in Freight transportation. Freight rail companies have to consider the fact that some customers are working with JIT or other time critical delivery approaches while other customers contemplate punctuality as a more important requirement [17]. Customers' requirements need to be investigated in order to establish an acceptable classification of customer groups [18]. Another aspect to take into consideration is that some customers are willing to pay more to get extra services and rail freight companies should take advantage of this situation as much as possible [17].

\subsection{Traffic variation: weekly and daily}

One of the current problems in trip planning is that wagons are simply booked into the earliest available train without any consideration to the train. When the train is full, overbooked wagons will have to be delayed until the next available train, which is typically 24 hours later. There are two types of traffic variability; first there is seasonal or weekly traffic variability and then there is daily traffic variability [17]. Seasonal traffic variation is a difficult aspect to modify, as it is dependent of customer or market demands, and causes that freight companies have to dimension their resources needs according to those periods which higher activity rates. The main advantage of this type of traffic variability is that it can usually be planned ahead, aspect allowing freight firms to plan their activities in a more efficient way. The weekly traffic variation is a more difficult concept to work with and control, as it varies depending on the daily production levels of the customers. It is not possible to deal with those problems linked to peaks in daily demand using predetermined blocking concepts, which do not vary with day of week or actual operating conditions [17]. The problem with having 
variation and peaks during some specific hours as well as days obviously limits the capacity on the whole rail system but it also affects the customer promises of punctuality and service to the customers during these periods [19].

\section{Areas of improvements}

Three main problem areas for improvements identified within capacity optimization for the studied case are optimization of train capacity concerning the weight and length in trains; peak reduction of the train traffic and uneven flow of freight trains throughout the week.

\subsection{Optimization of train capacity}

The maximum allowed load per train is constrained by train length and weight, both of them limited by legislation. In addition, maximum weight is also dependant on geographical and infrastructural conditions as well as engine power. Two of the main physical constraints affecting the maximum train capacity are identified as weight and length limitations. According to legislation, maximum allowed train length corresponds with 600 meters whereas there are two different weight limitations are dependent on the geographical situation of the rail, Ange station represents the key point regarding this aspect: trains heading north from the city are limited to a weight of 1100 tons, whilst the maximum permitted weight for trains south from the city is 1600 tons. This fact is also connected the locomotives power specifications, which needs to reduce its maximum transported weight as more unfavourable geographical conditions occur. However all activities related to shunting, sorting and building new trains in order to adapt them to the different weight limitations are done in Borlänge because its rail yard is considered to be more suitable than the Ånge one to perform those activities. This represents an important constraint for optimizing the capacity of the trains. Therefore a possible solution would be in moving all these activities to Ånge instead of Borlänge as the practical weight limit location, hence avoiding the current unnecessary weight limitation between these two cities and allowing to increase on 500 tons the transported weight of those trains travelling along the route.

The company only traces and analyses capacity values regarding length and weight limitations for long-distance trains. Capacity values regarding train length optimization are calculated considering the final length of each sent train in comparison with its maximum possible value, 600 meters. The average figure of train length capacity optimization during the mentioned period presented a value of $65.58 \%$. Capacity values related to train weight optimization are calculated establishing a weight target of 1300 tons, which approximately represents the average value between weight limitations on those railways further north and further south than Ånge, with 1100 and 1600 tons respectively. Nevertheless, several reasons let us consider that 1300 tons does not represent a realistic overall target value in order to calculate train utilization of weight capacity. This figure represents an average value of the two allowed weight limits all over 
Sweden, but the reality shows that train volume further north than Ånge is far from representing the $50 \%$ of the overall transported freight figures. Because of that, monthly weight capacity values present higher values than those that would be obtained in case of using a most accurate target value. It would be interesting to calculate weight optimization values for each train according to their real weight limitations in order to have a more precise and realistic view of their current situation. Train capacity figures are calculated for each train covering a long-distance route after its real length and weight values are reported to the system. However, although those data are available they are not analysed on a daily basis. At present, operational departments are in charge of making sure not to exceed length and weight train limitations before a train is allowed to leave, and real train capacity figures are calculated once the train has been sent. Therefore a solution might be in increasing fill rates on those trains covering short and medium distances.

\subsubsection{Allocation of real capacity needs}

The overall capacity needs for the next year are planned according to historic data as well as yearly forecasting estimations made by the Market division. The company gets time slots around September of the previous planned year. Since that moment a complex process of route creations, managing empty wagons flow or allocating locomotive and operator resources starts. At the latest, six weeks prior to train departure, it is possible to adapt automatically (not in a manual way), the planned activities in the software according to changing customer requirements. The last step affecting the final train capacity values is related to the departments in charge of daily coordination of the real train traffic. Some of the problems faced by these "short-term" departments can be related with customer delays when preparing the goods to transport, changing orders or last minute cancellations.

The future objective is three years forecasting processes, aspect which will optimize the future capacity needs estimations and will provide the planning departments more time in order to adapt and modify the existing production plans to the real capacity requirements. At present, when the slot is allocated for the next year to a certain rail company, this company has the possibility of cancelling that slot free of charge before planned train departure time. This situation causes some rail companies to book certain time slots in case they might need them because it does not cost anything to cancel. However, that creates confusion and last minute cancelations and therefore in the future, the companies will be charged a certain fee for slot allocations. A more accurate forecasting regarding future volumes will allow the company to apply for those required time slots, avoiding losing money due to cancelations.

There are a large number of software programs for plan and control of the activities, however the same are not fully utilized and communication between them is not very efficient in some occasions. The company should actively work on coordination of its software programs used by the different departments in order to facilitate and shorten the decision process. This suggestion would 
significantly improve the day-to-day management and coordination, because only during 2012 there were more than 30,000 "last-minute" changes, meaning a really considerable amount of working hours analysing those aspects.

Operational planning and control departments are in charge of directing shunting operations as well as determining the final wagons allocation for each train. However those departments are not always aware about some important company policies regarding train cancellations. The problem is that they try to maximally utilise the on-going train capacity by reallocating the wagons from other trains, which is good for that train utilization but interrupts the schedule that creates other kind of problems at the final destination. In order to eliminate this problem periodical short courses and meetings at the different company departments intended to inform about the new company policies should be performed.

\subsubsection{Blocking policy}

Three different contract types are to offer to customers: single wagons, fixed delivery and dedicated trains; and according to the company the biggest potential area of improvement. The "anchor block" concept is considered very useful approach to optimize train capacity in those cases in which various customers share a train then the remaining train capacity, after considering anchor block customer demands, can be completed by other customers contracting "single wagons". With that concept each customer would apply for certain capacity and the different customer requests would be combined to create a more optimized train, regarding the weight and length. One way to achieve this is by mixing light and heavy freight from different branches. The new blocking policy would also offer customers an option of getting a fixed delivery time and priority over other customers by paying an extra fee.

At present, some very important customers operating on dedicated trains do not want to share their trains with other customers, although not fully loaded. They prefer to pay for the whole train capacity although they do not use it, to avoid problems such as delivery delays caused by other customers. Mixed blocking policy, negotiations and better marketing of "anchor blocks" could result in change of behaviour with those important customers. Considering that the company does not have enough resources to exploit available software, and good IT system is crucial for this performance, the new blocking policy seems to be far too resource demanding to be implemented.

\subsection{Peak reduction of the night train traffic}

Most of freight train transportation takes place during night hours [20]. The company's freight transport is mostly performed during weekdays, especially from Monday to Thursday; whereas during Friday, Saturday and Sunday the volume is much lower. This is due to the company's services to industry, which normally operates during weekdays and reduces its activity levels during the weekend. The highest locomotive activity rates happen during 22:00-02:00 from Sunday night until Friday morning. During those peak service hours around 120 locomotives are in use at the same time, whereas in the intervals between 
06:00-12:00 from Monday to Friday, only about 70 locomotives are used. During weekends freight transportation shows lowest activity rates.

Swedish legislation sets weekly working times limited to 40 hours in which employees cannot work over 23:00. However the transportation services are mainly carried out during night hours, which creates the need for special night regulations. Since the passenger transport has the priority and Swedish Transport Administration decides about available slots, not many improvements are possible in this area on the internal level. The only hope lies in the European Union objectives and future regulations for promotion of freight on rail that would make it more viable [20]. However some "anchor block" customers demand night transport since it fits into their schedules and those should not be changed although some time requirements are mainly influenced by industry traditions, and not actual needs. Another potential solution is to reconsider and re-evaluate existing "anchor block" customer since the same have been labelled like this since long ago.

Swedish railway can be divided in three pricing categories: red, yellow and green, representing respectively the most and least expensive railways [21]. One option could be redirecting the transport to routes through a yellow and green-categorized railway. Careful route planning and scheduling would be required for this rerouting.

\subsection{Reduction of the uneven flow of freight trains}

Uneven flow occurs during the day, week, month and year; and for different reasons. Some improvement suggestions are presented below.

\subsubsection{Weekly variations of freight transport}

Freight transportation is closely related to industrial activities, which present the highest production rates mainly during weekdays [17]. In addition to the uneven freight traffic between weekdays and weekend days, it is also important to consider the uneven freight flow during weekdays (see Figure 1). Traditionally, Tuesday and Thursday have represented those days with higher freight train flow. In the last years the company has done important measures to balance out the uneven freight flow during the weekdays. One of the adopted measures was to manually allocate new customer bookings to Monday and Friday, days presenting less freight traffic. Apart from trying to establish contracts with new customers mainly during those days with less traffic volume, the company should analyse its current customer needs and demands. It is very likely that certain old customers could accept some modifications on their agreed delivery days, providing the possibility of establishing a more even weekly freight flow. Some of the benefits linked to the reduction in the weekly traffic variation are the establishment of better planning processes, the achievement of increased punctually precision and the resources optimization. An even traffic volume would allow to dimension both engines and personnel requirements according to the highest activity rates, which are supposed to be quite similar during the different weekdays. 


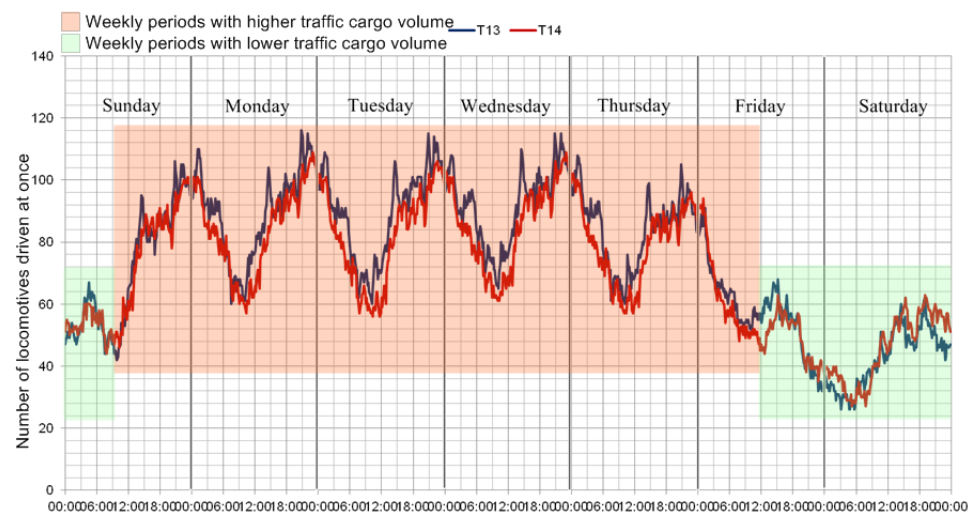

Figure 1: Average utilization of locomotives during weekdays in 2013 (company's internal document).

\subsubsection{Reduction of number of engine types}

The company has a total of 18 types of engines, diesel and electrical engines. The diesel engines are more used in shunting, because electricity is not available on all shunting yards. The newer electrical engines are used for longer distances. There are also other differences between the types, making the variation and final number of distinct engines even higher; altogether demanding different training for the drivers, the shunters and the mechanics. Therefore matching engine with a suitable driver is an important part of planning the schedules. This variety of engines makes it challenging to keep an even flow on the traffic as there always has to be a specific engine with specifically trained personal at the correct location to provide the transport service.

If a reduction in different types of locomotives would be achieved, there would be fewer problems with locomotives and drivers allocation process. In addition, equipment and education of drivers and shunters could be standardized, providing more flexibility to adapt employees to the different locomotive resources.

\subsubsection{New blocking policy and introduction of a categorization system}

The current company's booking system stands that the first customer in booking services will get the first available slot. This policy is applied only to those customers having contractual relations of the type "single wagons". The policy first booked first served can be considered to be as one of the causes of the uneven transportation flow during the weekdays. This booking system does not consider any priority category. For example, in certain occasions, some orders not considered to be really profitable from the economic point of view are accepted whereas other orders considered to be much more worthy to work with cannot be accepted because they have been ordered later. New priority categorization system could facilitate introduction of modifications related to the current customer booking system. Those changes in the booking system were expected to stimulate customers to book their orders with more time in advance 
and plan their wagon requirements in a more accurate way. That would result in more flexibility for allocating orders to the different scheduled trains. Consequently, a more even transportation flow during the weekdays could be created. Furthermore, the suggested customer priority system should also consider customer loyalty levels. Customers can be categorized in two main categories: regular and non-regular. Regular or loyal customers present very constant and regular bookings and the company should reward those regular customers over non-regular ones.

\section{Conclusion}

Optimization of train capacity, reduction of the uneven flow and peak reduction of the train traffic are actually very overlapped and hard to discuss separately since change in one area might have consequences to other area. The goal with the study was to analyse and evaluate the feasibility of identified improvements related to capacity utilization and to suggest the implementation of those that could increase the efficiency of the services. Conclusion from the analysis and therefore a suggestion is to focus on the further implementation of concepts such as "local planning" and/or "anchor blocks", instead of on focusing of improving each specific capacity area. Although all identified improvements together would contribute to significant efficiency improvements, the same are very time demanding and require lot of advanced planning and major changes in the existing system. During this study some other areas for improvement have been identified such as single shunting or staff centralization, however the same are not covered here but will be presented separately.

\section{References}

[1] EC, (2013). The Fourth Railway Package - Completing the single European railway area to foster European competitiveness and growth, available at (accessed 12 December 2013):

http://eur-lex.europa.eu/LexUriServ/LexUriServ.do?uri=COM:2013:0025: FIN:EN:PDF

[2] European Commission (2012). Report from the commission to the council and the European Parliament - Third report on monitoring development of the rail market. Brussels.

[3] European Union. (2012). EU Transport in Figures 2012. Luxembourg: Publications Office of the European Union.

[4] Roso, V. (2007). Evaluation of the dry port concept from an environmental perspective, Transportation Research Part D, Vol. 12, No. 7, pp. 523-527.

[5] Commission of the European Communities, (2001). White Paper: European transport policy for 2010. Brussels: European Union.

[6] Port of Gothenburg, (2013). Rail Services, Annual Report, Gothenburg.

[7] Trafikverket, (2012). Transportsystemets behov av kapacitetshöjande åtgärder - förslag på lösningar till år 2025 och utblick mot år 2050. Publikationsnummer: 2012:100. ISBN: 978-91-7467-298-5. 
[8] Roso, V., Styhre, L., Woxenius, J., Berqvist, B. and Lumsden, K. (2014) Sustainability via Short Sea Shuttle Concept. UNF International Business Conference on Teaching Research and Practice - 14, USA.

[9] Voss, C.; Tsikriktsis, N. and Frohlich, M., (2002). Case research in operations management. International Journal of Operations and Production Management, 22(2), pp. 195-219.

[10] Golicic, S. L. and Davis, D. F., (2012). Implementing mixed methods research in supply chain management. International Journal of Physical Distribution and Logistics Management Vol. 42 No. 8/9, pp. 726-741.

[11] Ejvegård, R. (2003). Vetenskaplig metod. Lund: Studentlitteratur AB.

[12] Gibson, S. (2003). Allocation of capacity in the rail industry. Utilities Policy, pp. 39-42.

[13] Vierth, I., Mellin, A., Hylén, B., Karlsson, J., Karlsson, R., \& Johansson, M. (2012). Kartläggning av järnvägstrafiken i Sverige. Linköping: Swedish National Road and Transport Research Institute.

[14] Abrahamsson, E. (2010). Höghastihetsbanor - ett samhällsbygge för stärkt utveckling och konkurrenskraft. Swedish National Road and Transport Research Institute (1), p. 13.

[15] Abril, M., Barber, F., Ingolotti, L., Salido, M. A., Tormos, P. \& Lova, A. (2008). An Assessment of Railway Capacity. Valencia: Elsevier.

[16] Cordeau, J.-F., Toth, P. \& Vigo, D. (1998). A Survey of Optimization Models for Train Routing and Scheduling. Transportation Science, pp. 380-404.

[17] Kwon, O. K., Martland, C. D., \& Sussman, J. M. (1998). Routing and scheduling temporal and heterogeneous freight car traffic on rail networks. The Korea Transport Institute. Seoul: Transportation Research Part E.

[18] Crainic, T. G. (1998). A Survey of Optimization Models for Long-Haul Freight Transportation. Montréal: Department of Management and Technology.

[19] Bowersox, D. J. (2000). The Strategic Benefits of Logistics Alliances. Harvard Business Review, 36.

[20] Pricewaterhouse Coopers. (2008). European Union Preparatory study for an impact assessment for a rail network giving priority to freight. European Commission.

[21] Trafikverket. (2013). Järnvägsnätsbeskrivning. Borlänge: Trafikverket. 